\title{
Sex-specific disease outcomes of HIV-positive and HIV-negative drug users admitted to an opioid substitution therapy program in Spain: a cohort study
}

Roberto Muga ${ }^{*}$, Inmaculada Rivas², Eva Faure ${ }^{2}$, Daniel Fuster ${ }^{3}$, Paola Zuluaga', Manuela Rubio², Trinidad Muñoz ${ }^{2}$, Marta Torrens ${ }^{4}$, Jordi Tor ${ }^{1}$ and Arantza Sanvisens ${ }^{1}$

\begin{abstract}
Background: Opioid substitution therapy has improved the survival of heroin users with and without HIV infection. We aimed to analyze sex differences in mortality rates and predictors of death among those admitted to a methadone treatment program (MTP).

Methods: Longitudinal study of patients enrolled in a MTP from 1992 to 2010. Socio-demographic and drug use characteristics, and markers of viral infections were assessed at entry. Vital status was ascertained by clinical charts and the mortality register. Four calendar periods were defined according to the introduction of preventive and treatment interventions in Spain. Predictors of death were analyzed by Cox regression models.

Results: 1,678 patients (82.8\% men) were included; age at first heroin use was 18.6 years (IQR: 16-23 years), and age at first entry into a MTP was 30.7 years (IQR: 26-36 years). A total of 441 (26.3\%) deaths occurred during 15,124 person-years ( $p-y)$ of follow-up (median: 9.2 years, IQR: 4-13 years). HIV infection was the main predictor of death in men ( $\mathrm{HR}=3.5,95 \% \mathrm{Cl}: 2.1-5.7)$ and women ( $\mathrm{HR}=3.2,95 \% \mathrm{Cl}: 1.2-8.7)$ and main cause of death was HIV/AIDS. Overall mortality rate was 2.9 per 100 p-y (95\% Cl: 2.7-3.2 per 100 p-y) and death rates decreased over time: 7.4 per 100 p-y (95\% Cl: 6.3-8.8 per 100 p-y) for the 1992-1996 period to 1.9 per 100 p-y (95\% Cl: 1.6-2.4 per 100 p-y) for the 2007-2010 period. In women, a slightly increase in mortality was observed in recent periods specifically among HIV-positive women (3.7 per 100 p-y in period 2002-2006 and 4.5 per 100 p-y in 2007-2010).
\end{abstract}

Conclusions: Significant reductions in mortality of patients in MTP are observed after nineteen years of observation. However, HIV infection shows a great impact on survival, particularly among HIV-infected women.

Keywords: Methadone, Opioid substitution treatment, Mortality, HIV

\section{Background}

It has been estimated that 1.35 million people are heroin users in European countries [1]. Heroin dependence is a chronic disease characterized by compulsive drug-taking behavior despite serious negative consequences and, specifically, injection drug users (IDUs) have high prevalence of severe co-morbidities including blood-borne infectious diseases, drug overdose, and psychiatric disorders [2-4].

\footnotetext{
*Correspondence: rmuga.germanstrias@gencat.cat

'Department of Internal Medicine, Hospital Universitari Germans Trias i Pujol, Universitat Autònoma de Barcelona, 08916 Badalona, Spain

Full list of author information is available at the end of the article
}

The efficacy of detoxification as the main treatment intervention is limited, as compared to other therapeutic options such as opioid substitution therapy (OST) [5]. OST reduces heroin consumption by acting as opioid receptor agonists on the central nervous system. A reduction in heroin use further increases adherence to substitution therapies and facilitates the implementation of harm-reduction interventions aimed to improve quality of life and health [5-9]. Such health and social interventions while in substitution therapy are common for Methadone Treatment Programs (MTP). MTPs have been used since the mid-1960 in the United States (U.S.) [10] and more 
recently in Western Europe. Over 20 years of scientific evidence has demonstrated the effectiveness of OST on reducing the impact of illegal opiate usage in society $[11,12]$. Most importantly, treatment with methadone has been shown to reduce the risk of death as compared to no treatment [13]. Treatment with methadone also reduces the risk of blood-borne infections such as human immunodeficiency virus (HIV); methadone treatment in combination with needle exchange programs and other harm reduction strategies has been shown to reduce the risk of hepatitis C virus (HCV) infection [14-16].

In Western Europe, the experience of OST for the treatment of heroin dependence is heterogeneous. In most countries, including Spain, methadone is the preferred drug for OST, while buprenorphine is more common in others [17]. Approximately 90,000 patients receive methadone treatment in Spain, and this figure has remained constant since the early 1990's, when OST was focused to reduce the impact of HIV/AIDS and drug overdose [17]. Spanish drug users were heavily impacted by HIV infection to a point that there was a reduction in life expectancy for the general population during the early 1990's [18]. Despite the impact that heroin dependence had in young adults from urban settings, studies examining long-term disease outcomes from MTPs in Spain are scarce $[7,19]$.

The aim of this study was to analyze the survival of heroin users and predictors of death in a cohort of patients admitted to a MTP. Specifically, we aimed to analyze sex differences in mortality, as well as temporal changes over four calendar periods, which are characterized by the introduction of preventive and treatment interventions in metropolitan Barcelona, Spain. In doing so, our results will inform how MTP is implemented in our area.

\section{Methods}

A longitudinal study of patients admitted to a MTP from January 1992 to December 2010 was performed. This MTP began in January 1992, is the only OST in the metropolitan area that is north of Barcelona, and is located in the CAS-Delta, Municipal Institute for Personal Services, in Badalona. The CAS-Delta is a primary care center for outpatient addiction treatment, and serves an area with 400,000 inhabitants over five municipalities, including Badalona (240,000 inhabitants) and Santa Coloma de Gramenet (120,000 inhabitants). Within the program, methadone is dispensed via a primary care center, a mobile unit since 1993 and five community pharmacies since 1999.

MTP admission criteria were as follows: patients had to be $>18$ years old, and had to have an opioid dependence according to the Diagnostic and Statistical Manual of Mental Disorders, $4^{\text {th }}$ edition (DSM-IV) criteria. Psychosocial interventions and harm reduction programs, such as needle exchange, condom distribution, and supervised injection facilities, complemented the drug treatment program. Patients were referred to other Primary Care outpatient facilities or hospitals in the area for additional studies, if necessary. Additional MTP details have been published elsewhere [20].

Socio-demographic data (age at admission, education level, employment status, and prior imprisonment), drug use characteristics (age at first consumption, duration and route of administration), blood samples to test for $\mathrm{HIV}, \mathrm{HBV}(\mathrm{HBcAb}+)$, and $\mathrm{HCV}$ infections, and psychiatric history were collected at MTP admission. Information was obtained from medical records.

The psychiatric disorders were diagnosed by specialist at the MTP or other centers, and were divided into four categories: 1) mood-related disorders, 2) anxiety disorders, 3) schizophrenia or other psychotic disorders, and 4) personality disorders.

To analyze changes over time, four different time periods were established according to the introduction of preventive and treatment interventions in Barcelona, Spain: 1) 1992-1996: characterized by the development of methadone treatment and needle exchange programs. At the same time, antiretroviral therapy (ART) emerged as a treatment for HIV infection with monotherapy or dual therapy of nucleotide analogues [21], 2) 1997-2001: period that saw the widespread introduction of Highly Active Antiretroviral Therapy (HAART), 3) 2002-2006: period when HAART was simplified and supervised injection facilities for IDUs were created [22-24], and 4) 2007-2010: period that represented the consolidation of harm reduction interventions and the treatment of HIV infection with HAART in once-daily dosing.

The present study is compliant with ethical standards for medical research and good clinical practice principles, in accordance with the World Medical Association's Declaration of Helsinki. The study was approved by the Ethics Committee of the Hospital Universitari Germans Trias i Pujol and written consent of patients was obtained.

\section{Follow-up, mortality and cause of death}

Mortality and cause of death were ascertained by reviewing clinical charts and crosschecking with the Catalonian mortality register, as of December 31st, 2010.

Cause of death was established in accordance with the International Classification of Diseases, Version 9 (ICD-9) until 1998 [25], and Version 10 (ICD-10) between 1999 and 2010 [26]. Causes of death were later classified into four categories:

1) Non-natural (including drug-related and alcohol-related accidents, suicides, and traumas): ICD-9: 304, 305, and E800 - E999; ICD-10: 
F10 - F19, X00 - X99, V00 - V99, W00 - W99, and Y00 - Y36.

2) HIV/AIDS: ICD-9: 279.5 and 795.8; ICD-10: B20 - B24 and R75.

3) Liver-related (including viral hepatitis, cirrhosis, decompensated liver disease, and hepatocellular carcinoma): ICD-9: 070, 155, and 570-573; ICD-10: B15 - B19, C22, and K70 - K77.

4) Other medical causes, including non-HIV/AIDSrelated infectious diseases, and respiratory and central nervous system disorders (codes not specified in other categories).

\section{Statistical analysis}

Descriptive statistics were expressed as the median (interquartile range [IQR]) for continuous variables and as absolute frequencies and percentages for categorical variables. We used $\mathrm{X}$-square tests, Fisher F-tests, and Student's t-test to detect significant differences. Patients' entry to the cohort was defined by the first admission to MTP; all patients were followed until December $31^{\text {st }} 2010$ or death.

Cox regression models were used to analyze the predictors of death. Previous to the implementation of statistical models we checked for the proportional hazards assumption of all variables. The covariates used for multivariate analysis were those that were found to be statistically significant in univariate analysis. Stepwise forward selection was used to identify predictors establishing $\alpha=0.05$ and $\alpha=0.1$ as the inclusion and exclusion criteria, respectively.

Mortality rates were calculated in person-years (p-y) analysis; $\mathrm{p}-\mathrm{y}$ represents the time that all persons contribute to a longitudinal study. Rates of mortality in $p-y$ analysis are the quotient of the number of deaths observed during the study period in the numerator and the sum of all the individual follow-up times in the denominator. Temporal changes in mortality rates were observed for four periods: 1992-1996, 1997-2001, 2002-2006, and 2007-2010.

All analyses were conducted using two-sided tests and a significance level of 0.05. Descriptive statistics and regression models were generated using SPSS 15.0 (SPSS, Chicago, IL, USA). Mortality rates for the calendar years were calculated using STATA version 8.0 (Stata Corp., College Station, TX, USA).

\section{Results}

The study included 1,678 patients ( $82.8 \%$ men). The median age of first heroin use was 18.6 years (IQR: 16-23 years), median age at MTP admission was 30.7 years (IQR: $26-36$ years) and $23.8 \%$ of patients were non-IDUs. Forty four percent of patients were employed, $83 \%$ had completed primary education, and $48 \%$ had prior incarceration.
Psychiatric co-morbidities were analyzed for 1,567 patients; 25\% (394) were diagnosed with psychiatric disorders, and 22\% (87/394) had more than one disorder. The most frequent diagnoses were related to mood disorders in $45.9 \%(181 / 394)$, personality disorders in $34.2 \%(135 / 394)$, and anxiety in $17.7 \%$ (70/394). Twelve percent (48/394) of patients were diagnosed with a psychotic disorder, and 8.4\% (33/394) had previously attempted suicide.

The characteristics of patients by sex are described in Table 1. Men were more likely to have prior incarceration and women were more likely to be HIV-infected $(59.8 \%$ vs. $52.5 \%, p=0.040)$ and to have psychiatric co-morbidities $(30.3 \%$ vs. $24.1 \%, p=0.031)$, especially mood disorders.

\section{Follow-up and outcomes}

Overall, the median follow-up time for the entire cohort was 9.2 years (IQR: 4-13 years), while the total follow-up was 15,124 p-y. At the end of follow-up, 441 (26.3\%) patients had died and 14 (3.2\%) of deaths occurred within one month of first entry to treatment. The overall mortality rate was 2.9 per 100 p-y (95\% Confidence Interval (CI): 2.6-3.2 per $100 \mathrm{p}-\mathrm{y})$, and the main causes of death

Table 1 Baseline characteristics of 1,390 men and 288 women admitted to a methadone treatment program in metropolitan Barcelona, Spain, between 1992 and 2010

\begin{tabular}{|c|c|c|c|}
\hline & $\begin{array}{c}\text { Men } \\
n=1,390 \\
n(\%)\end{array}$ & $\begin{array}{c}\text { Women } \\
n=288 \\
n(\%)\end{array}$ & $p$ value \\
\hline Age at admission (median, IQR) & $31(26-36)$ & $30(24-35)$ & 0.000 \\
\hline Period of admission: & & & 0.972 \\
\hline 1992-1996 & $505(36.3)$ & $103(35.8)$ & \\
\hline 1997-2001 & $469(33.7)$ & $97(33.7)$ & \\
\hline $2002-2006$ & $250(18.0)$ & $55(19.1)$ & \\
\hline $2007-2010$ & $166(11.9)$ & $33(11.5)$ & \\
\hline \multicolumn{4}{|l|}{ Social and drug use characteristics } \\
\hline $\begin{array}{l}\text { Age at first heroin use } \\
\text { (median, IQR) }\end{array}$ & $19(17-22)$ & $19(16-24)$ & 0.940 \\
\hline Injection drug use $(n=1,562)$ & $992(76.8)$ & $198(73.1)$ & 0.184 \\
\hline Unemployed $(n=1,560)$ & $703(54.5)$ & $164(60.5)$ & 0.072 \\
\hline $\begin{array}{l}\text { Primary school attainment } \\
(n=1,552)\end{array}$ & $1,065(83.1)$ & $223(82.3)$ & 0.735 \\
\hline Prior incarceration $(n=1,480)$ & $610(49.8)$ & $100(39.4)$ & 0.003 \\
\hline \multicolumn{4}{|l|}{ Co-morbidity } \\
\hline HIV infection $(n=1,343)$ & $582(52.5)$ & $140(59.8)$ & 0.040 \\
\hline HCV infection $(n=727)$ & $443(73.2)$ & $92(75.4)$ & 0.617 \\
\hline $\begin{array}{l}\text { HBV infection (HBcAb+) } \\
(n=708)\end{array}$ & $369(62.2)$ & $65(56.5)$ & 0.250 \\
\hline $\begin{array}{l}\text { Psychiatric disorder } \\
(n=1,567)\end{array}$ & $311(24.1)$ & $83(30.3)$ & 0.031 \\
\hline
\end{tabular}


were HIV/AIDS (40\%) and non-natural (26.4\%) (Table 2). No sex differences were observed for the median follow-up ( $p=0.097)$, cumulative mortality $(p=0.403)$, or mortality rate $(p=0.187)$. However, distribution of the causes of death was significantly different between sex $(p=0.022)$; HIV/AIDS-related mortality was higher in women (53.0\% vs. $37.3 \%)$ and mortality from non-natural causes was higher in men (29.0\% vs. $12.1 \%)$.

\section{Sex-specific predictors of death}

In the univariate analyses, age at admission, antecedent of IDU, HCV, HIV and HBV infections at admission, prior incarceration, and period of admission to MTP were associated with mortality among men. In the multivariate analysis, only HIV infection at admission was an independent predictor of death (Table 3).

Among women, age at admission, antecedent of IDU, HBV and HIV infection at admission, and prior incarceration were associated with mortality in the univariate analyses. In multivariate analysis, only HIV infection at admission and prior incarceration were predictors of death (Table 3 ).

\section{Mortality trend and causes of death}

Overall mortality rate decreased over time: 7.4 per 100 p-y (95\% CI: 6.3-8.8 per 100 p-y) for 1992-1996, 2.7 per 100 p-y (95\% CI: 2.2-3.3 per 100 p-y) for 1997-2001, 2.4 per 100 p-y (95\% CI: 2.0-2.9 per 100 p-y) for 2002-2006, and 1.9 per 100 p-y (95\% CI: 1.6-2.4 per 100 p-y) for 2007-2010. A statistically significant reduction $(p<0.005)$ for all pairwise relative risk of death was observed using the first period as the reference category.

Mortality in women slightly increased during recent periods. While the initial mortality rate decreased from 4.4 per 100 p-y (95\% CI: 2.6-7.4 per 100 p-y) in 1992-1996 to 1.8 per 100 p-y (95\% CI: 0.9-3.2 per

\begin{tabular}{|c|c|c|c|}
\hline & $\begin{array}{c}\text { Men } \\
n=1,390\end{array}$ & $\begin{array}{l}\text { Women } \\
n=298\end{array}$ & $p$ value \\
\hline Total follow-up length (p-y) & 12,356 & 2,768 & \\
\hline Median follow-up (IQR), years & $9.1(3.8-12.8)$ & $9.6(4.9-13.8)$ & 0.097 \\
\hline Deaths, n (\%) & $371(26.7)$ & $70(24.3)$ & 0.403 \\
\hline $\begin{array}{l}\text { Mortality Rate, per } 100 \text { p-y } \\
(95 \% \text { Cl) }\end{array}$ & $3.0(2.7-3.3)$ & $2.5(2.0-3.2)$ & 0.187 \\
\hline Causes of death $(n=425)$ & & & 0.022 \\
\hline HIV/AIDS & $134(37.3)$ & $35(53.0)$ & \\
\hline Non-natural & $104(29.0)$ & $8(12.1)$ & \\
\hline Liver & 38 (10.6) & $8(12.1)$ & \\
\hline Other & $83(23.1)$ & $15(22.7)$ & \\
\hline
\end{tabular}

100 p-y) in 1997-2001, it increased to 2.7 per 100 p-y (95\% CI: $1.8-3.9$ per $100 \mathrm{p}-\mathrm{y})$ in the 2002-2006 period and 2.2 per 100 p-y (95\% CI: 1.4-3.5 per 100 p-y) in 2007-2010. This increase in mortality rates was most apparent for the HIV-infected women. Figure 1 shows the temporal trend of mortality rates by sex and HIV status.

To analyze the recent increase in mortality of HIVinfected women, the specific causes of death were reviewed since January 2002. The main causes of death among the 33 HIV-positive women were AIDS-related (53.3\%) and liver-related (10\%) and few of them (6.7\%) died from non-natural causes. The main causes of death among the $116 \mathrm{HIV}$-positive men who died in the same periods were AIDS-related (33.6\%), liver-related (16.8\%), and non-natural (18.6\%). Overall, there were no statistically significant differences in the causes of death of HIVpositive men and HIV-positive women in the last periods $(p=0.154)$. However, during the last two periods HIV-positive women showed a higher proportion of AIDS-related deaths than HIV-positive men. $(p=0.048)$.

\section{Discussion}

This study provides a description of survival in opiatedependent men and women admitted to MTP and shows that HIV infection is the main predictor of death in this population. Women are more likely to be HIV-positive than men when they are admitted to OST which is consistent with a recent meta-analysis concluding that female IDU are more likely to acquire HIV infection [27]; in the present study IDUs represents $75 \%$ of cases.

On the other hand, women from this study were more likely to receive a diagnostic of psychiatric disorder than men which is also consistent with a previous study [22]. Psychiatric comorbidity in this series is high; up to $25 \%$ of patients had a mental health disorder before or upon admission to the MTP. However, prevalence of psychiatric disorders in patients with substance abuse is heterogeneous probably because differences in the diagnostic methods or due to the difficulty in obtaining psychiatric diagnoses for drug users $[28,29]$.

A systematic review of longitudinal studies found that the mortality of heroin-dependent patients varies across countries. Specifically, the pooled crude death rate for all cause mortality was $2.22 \times 100$ p-y in Western Europe [13]. The mortality of patients in MTP in the present study is even higher, probably due to the impact of HIV/AIDS on survival. Regarding other factors that may influence survival of patients admitted to an OST, we cannot exclude the role that methadone dosage changes and treatment interruptions may have on mortality, as this information that was not available.

In this study, deaths due to non-natural causes, including drug overdose, was significantly higher in men than in women. This finding is consistent with mortality data from 
Table 3 Cox regression models for predictors of death in 1,390 men and 288 women admitted to a methadone treatment program in metropolitan Barcelona, Spain, between 1992 and 2010

\begin{tabular}{|c|c|c|c|c|c|c|c|c|}
\hline & \multicolumn{4}{|c|}{ Men } & \multicolumn{4}{|c|}{ Women } \\
\hline & \multicolumn{2}{|c|}{ Univariate } & \multicolumn{2}{|c|}{ Multivariate $^{1}$} & \multicolumn{2}{|c|}{ Univariate } & \multicolumn{2}{|c|}{ Multivariate $^{2}$} \\
\hline & HR & $\mathrm{Cl} 95 \%$ & HR & $\mathrm{Cl} 95 \%$ & HR & $\mathrm{Cl} 95 \%$ & HR & $\mathrm{Cl} 95 \%$ \\
\hline Age at admission & 1.03 & $1.02-1.05$ & & & 1.04 & $1.00-1.08$ & & \\
\hline \multicolumn{9}{|l|}{ Period of admission } \\
\hline 1992-1996 & 2.33 & $1.18-4.59$ & & & 1.24 & $0.28-5.44$ & & \\
\hline 1997-2001 & 1.31 & $0.66-2.62$ & & & 0.90 & $0.20-4.02$ & & \\
\hline 2002-2006 & 0.96 & $0.45-2.01$ & & & 0.86 & $0.17-4.21$ & & \\
\hline 2007-2010 & 1 & & & & 1 & & & \\
\hline \multicolumn{9}{|c|}{ Social and drug use characteristics } \\
\hline Age at first heroin use & 1.01 & $0.99-1.03$ & & & 1.02 & $0.97-1.07$ & & \\
\hline Injection drug use & 2.87 & $1.97-4.18$ & & & 7.38 & $2.32-23.52$ & & \\
\hline Unemployed & 1.18 & $0.95-1.46$ & & & 0.98 & $0.59-1.62$ & & \\
\hline Primary school attainment & 1.27 & $0.97-1.65$ & & & 0.79 & $0.40-1.54$ & & \\
\hline Prior incarceration & 1.50 & $1.21-1.86$ & & & 2.53 & $1.50-4.26$ & 3.07 & $1.33-7.07$ \\
\hline \multicolumn{9}{|l|}{ Co-morbidity } \\
\hline HIV infection & 4.01 & $3.09-5.21$ & 3.5 & $2.09-5.74$ & 5.46 & 2.49-11.99 & 3.20 & $1.18-8.70$ \\
\hline HCV infection & 2.37 & $1.44-3.90$ & & & 3.42 & $0.80-14.61$ & & \\
\hline HBV infection (HBcAb+) & 1.45 & $1.02-2.05$ & & & 3.25 & $1.23-8.58$ & & \\
\hline Psychiatric disorder & 1.06 & $0.83-1.36$ & & & 0.70 & $0.39-1.26$ & & \\
\hline
\end{tabular}

Multivariate Cox regression with stepwise forward selection method. Statistically significant predictors are in bold ( $p<0.05)$.

${ }^{1}$ Multivariate analysis for men included age at admission, injection drug use, prior incarceration, HIV infection, HCV infection and HBV infection.

${ }^{2}$ Multivariate analysis for women included age at admission, injection drug use, prior incarceration, HIV infection and HBV infection.

European heroin users for whom the male:female ratio for drug overdose deaths is 4:1 [1]. However, a recent study on patients in a MTP demonstrated that the excess mortality due to non-natural causes is higher in women when the standardized mortality ratio is considered [30].

As it has been alredy mentioned, HIV/AIDS was a strong predictor of death, irrespective of gender. These results are consistent with others that have also shown a significant impact of HIV/AIDS on the survival of patients in a MTPs [7,31-33]. Furthermore, HIV infection in patients on OST is a surrogate of injection drug use; in fact, non-IDUs have a fivefold lower risk of HIV infection than IDUs, as shown in previous studies [34,35]. In addition, prior incarceration was a risk factor of death in women herein. Imprisonment before being admitted to an OST program may be an indicator

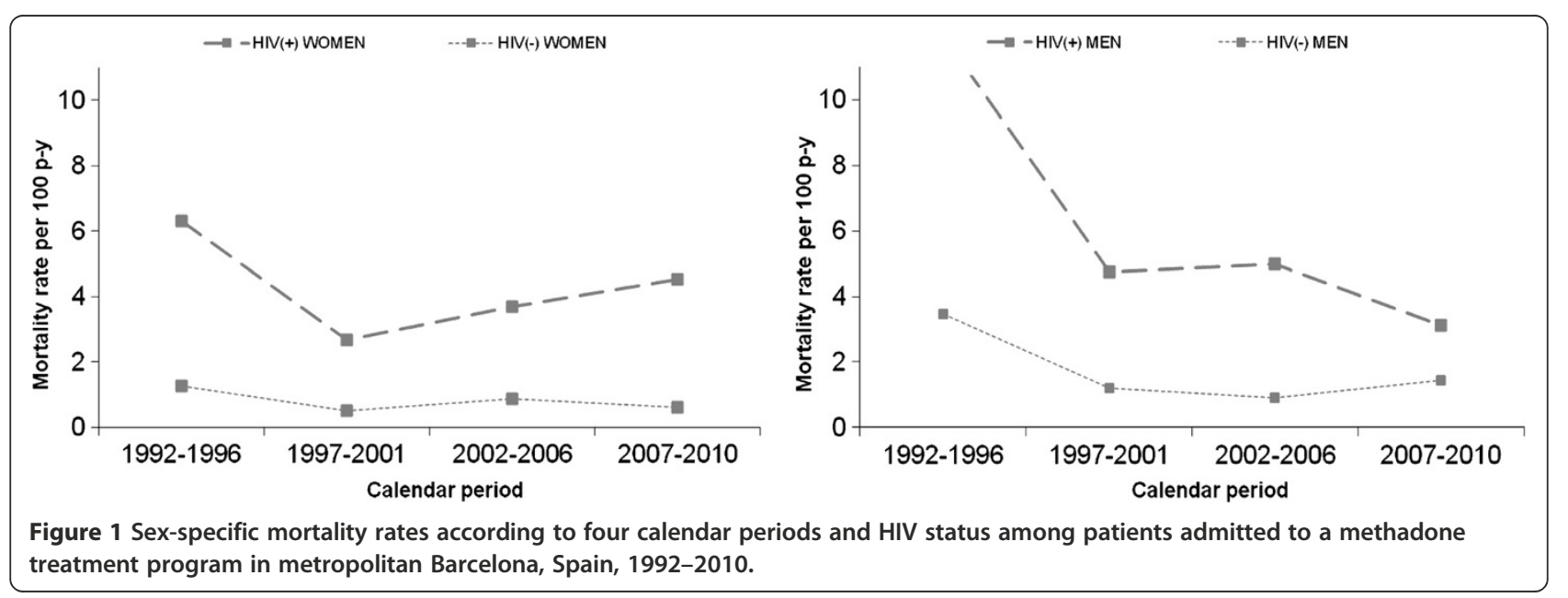


of low socioeconomic status and of the severity of drug dependence [36].

This study shows that overall mortality decreased over the two decades analyzed. Significant reductions in the mortality of heroin-dependent patients has been reported in Spain since 1995 [37]; the lower mortality was attributed to the progressive introduction of harm reduction interventions and the dissemination of OST programs.

Another finding of this study is the decline in the number of first time admissions to methadone treatment. Assuming that access to substitution treatment did not change over the study period, there are several potential explanations for the observed decline. First, a lower number of admissions may indicate fewer heroin users in the community; second, the emergence of other heroin substitutes, such as buprenorphine, may reduce the number of patients admitted to the MTP; and third, the irruption of supervised injection facilities in Spain may have produced a shift in attitudes of IDUs, favoring the use of injected heroin in a safe facility. Data from other health indicators support the hypothesis that the decrease in MTP patients may be associated with fewer heroin users in the Barcelona area [38].

This study has several limitations that should be mentioned. First, the number of available clinical and epidemiological variables is limited; thus, it is difficult to determine the impact of additional co-morbidities on survival. However, HIV/AIDS and HCV infections, two diseases with a great impact on survival of patients with a history of IDU, were included as covariates in our analysis [1]. Second, the frequency of poly-drug use while on methadone was not known; it is likely that concurrent use of cocaine and/or alcohol might be associated with an increased risk of death in this population [39]. Third, this study did not analyze neither changes over time regarding methadone dose and treatment interruptions nor changes in HIV and HCV serostatus; in this sense, methadone dose, treatment interruptions and blood-borne infections have been associated with disease outcomes $[33,40]$.

\section{Conclusion}

In conclusion, this study aimed to analyze disease outcomes in a large cohort of patients admitted to an MTP during 19 years of recruitment and follow-up. The MTP main characteristics have not changed since the program's inception in 1992 and it is the only MTP in an urban area with a population of 400,000. Adapting treatment delivery to patients' life conditions and improving the coordination of different health care levels is essential to improve survival of drug-dependent patients treated with methadone.

\section{Abbreviations}

ART: AntiRetroviral therapy; Cl: Confidence interval; HAART: Highly active antiretroviral therapy; HBV: Hepatitis B Virus; HCV: Hepatitis C Virus; HIV: Human immunodeficiency virus; HR: Hazard ratio; ICD: International classification diseases; IDU: Injection drug user; IQR: Inter quartil range; MTP: Methadone treatment program; OST: Opiate substitution therapy; p-y: person-years.

\section{Competing interests}

There are non-financial competing interests.

\section{Authors' contributions}

RM and AS designed the study and wrote the first draft of the manuscript. AS managed the literature searches and undertook the statistical analysis. IR, $E F, M R, T M$, recruited the study population. DF and PZ reviewed the literature and made substantial contributions to the interpretation of data. JT and MT critically reviewed multiple drafts of manuscript. All the authors contributed to the discussion section and revised and approved the final manuscript.

\section{Acknowledgements}

Funding sources: This work was supported by grants from the Ministry of Science and Innovation, Spain [RETICS grant numbers RD06/001/0021, RD06/006/1014, RD12/0028/006 and, RD12/0028/0009], the Agency for the Management of University and Research Grants-AGAUR [grant number 2008 BE-2 00269], the Ministry of Health [grant number EC11-042], the Municipal Institute for Personal Services [2009 Innovation Projects from Badalona city Council] and, with the collaboration of Gilead-Spain Fellowship Program. Dr. Fuster is a post-doctoral grantee from the Spanish Ministry of Education, Fundación Española para la Ciencia y la Tecnología [grant number EDU/3495/2010].

We would like to thank the health care professionals working at CAS Delta-Badalona, the mobile unit (Methadone Bus), and pharmacies dispensing methadone in Badalona and Santa Coloma de Gramenet, Spain for their contribution to the development and consolidation of the treatment program since 1992. We would like to thank local NGO members for the support they provide to patients, and for the implementation of harm-reduction interventions in the community.

This work has been made possible by the collaboration of the Mortality Register, Institute of Health Studies, Department of Health, Government of Catalonia.

\section{Author details}

'Department of Internal Medicine, Hospital Universitari Germans Trias i Pujol, Universitat Autònoma de Barcelona, 08916 Badalona, Spain. ${ }^{2}$ Municipal Centre for Substance Abuse Treatment (Centro Delta), Badalona, Spain. ${ }^{3}$ Section of General Internal Medicine, Boston Medical Center, Boston University School of Medicine, Boston, MA, USA. ${ }^{4}$ Institute of Neuropsychiatry \& Addictions, Parc de Salut Mar, Universitat Autònoma Barcelona, Barcelona, Spain.

Received: 30 January 2014 Accepted: 11 September 2014 Published: 17 September 2014

\section{References}

1. European Monitoring Centre for Drugs and Drug Addiction: Annual Report on the State of the Drugs Problem in Europe; 2011.

2. Deiss RG, Rodwell TC, Garfein RS: Tuberculosis and illicit drug use: review and update. Clin Infect Dis 2009, 48:72-82.

3. Litwin $A H$, Soloway I, Gourevitch MN: Integrating services for injection drug users infected with hepatitis $C$ virus with methadone maintenance treatment: challenges and opportunities. Clin Infect Dis 2005, 40(Suppl 5):S339-S345.

4. Regier DA, Farmer ME, Rae DS, Locke BZ, Keith SJ, Judd LL, Goodwin FK: Comorbidity of mental disorders with alcohol and other drug abuse. Results from the Epidemiologic Catchment Area (ECA) Study. JAMA 1990, 264:2511-2518.

5. Mattick RP, Breen C, Kimber J, Davoli M: Methadone maintenance therapy versus no opioid replacement therapy for opioid dependence. Cochrane Database Syst Rev 2009, 3:CD002209. 
6. Cornish R, Macleod J, Strang J, Vickerman P, Hickman M: Risk of death during and after opiate substitution treatment in primary care: prospective observational study in UK General Practice Research Database. BMJ 2010, 341:c5475.

7. Brugal MT, Domingo-Salvany A, Puig R, Barrio G, de García Olalla P, de la Fuente $L$ : Evaluating the impact of methadone maintenance programmes on mortality due to overdose and aids in a cohort of heroin users in Spain. Addiction 2005, 100:981-989.

8. Maremmani I, Pani PP, Pacini M, Perugi G: Substance use and quality of life over 12 months among buprenorphine maintenance-treated and methadone maintenance-treated heroin-addicted patients. J Subst Abuse Treat 2007, 33:91-98.

9. Seidenberg A, Rosemann T, Senn O: Patients receiving opioid maintenance treatment in primary care: successful chronic hepatitis $C$ care in a real world setting. BMC Infect Dis 2013, 13:9.

10. Dole VP, Nyswander M: A medical treatment for diacetylmorphine (heroin) addiction. A clinical trial with methadone hydrochloride. JAMA 1965, 193:646-650

11. Amato L, Davoli M, Perucci CA, Ferri M, Faggiano F, Mattick RP: An overview of systematic reviews of the effectiveness of opiate maintenance therapies: available evidence to inform clinical practice and research. J Subst Abuse Treat 2005, 28:321-329.

12. Bobes García J, Bobes Bascarán MT: Long term effectiveness of methadone maintenance treatments in persons with addiction to opiates. Adicciones 2012, 24:179-183.

13. Degenhardt L, Bucello C, Mathers B, Briegleb C, Ali H, Hickman M, McLaren J: Mortality among regular or dependent users of heroin and other opioids: a systematic review and meta-analysis of cohort studies. Addiction 2011, 106:32-51.

14. MacArthur GJ, Minozzi S, Martin N, Vickerman P, Deren S, Bruneau J, Degenhardt L, Hickman M: Opiate substitution treatment and HIV transmission in people who inject drugs: systematic review and meta-analysis. BMJ 2012, 345:e5945

15. Kimber J, Copeland L, Hickman M, Macleod J, McKenzie J, De Angelis D, Robertson JR: Survival and cessation in injecting drug users: prospective observational study of outcomes and effect of opiate substitution treatment. BMJ 2010, 341:C3172.

16. Hagan H, Pouget ER, Des Jarlais DC: A systematic review and meta-analysis of interventions to prevent hepatitis $C$ virus infection in people who inject drugs. J Infect Dis 2011, 204:74-83.

17. Torrens M, Fonseca F, Castillo C, Domingo-Salvany A: Methadone maintenance treatment in Spain: the success of a harm reduction approach. Bull World Health Organ 2013, 91:136-141.

18. Anonymous: La Salut a Barcelona 2001. Barcelona: Institut Municipal de Salut Pública de Barcelona, Ajuntament de Barcelona; 2003.

19. Jiménez-Treviño L, Saiz-Martínez PA, Gutiérrez Cienfuegos E, Bascarán Fernández MT, Carreño Rendueles E, de González-Quiros Menéndez Luarca M, González García-Portilla MP, Bobes García J: Valoración transversal tras quince años en una muestra de adictos a opiáceos en Asturias. Adicciones 2000, 12:507-513.

20. Sanvisens A, Rivas I, Faure E, Muñoz T, Rubio M, Fuster D, Tor J, Muga R: Characteristics of heroin dependent patients admitted to a methadone treatment program. Med Clin (Barc) 2014, 142:53-58.

21. HHS Panel on Antiretroviral Guidelines for Adults and Adolescents: Guidelines for the use of antiretroviral agents in HIV-1-infected adults and adolescents. Department on Health and Human Services; 2013 [http://aidsinfo.nih.gov/contentfiles/lvguidelines/AdultandAdolescentGL.pdf]

22. Torrens M, Gilchrist G, Domingo-Salvany A: Psychiatric comorbidity in illicit drug users: substance-induced versus independent disorders. Drug Alcohol Depend 2011, 113:147-156.

23. Viciana P, Rubio R, Ribera E, Knobel H, Iribarren JA, Arribas JR, Pérez-Molina JA: Longitudinal study on adherence, treatment satisfaction, and effectiveness of once-daily versus twice-daily antiretroviral therapy in a Spanish cohort of HIV-infected patients (CUVA study). Enferm Infecc Microbio/ Clin 2008, 26:127-134.

24. Martínez E, Arnaiz JA, Podzamczer D, Dalmau D, Ribera E, Domingo P, Knobel H, Riera M, Pedrol E, Force L, Llibre JM, Segura F, Richart C, Cortés C, Javaloyas M, Aranda M, Cruceta A, de Lazzari E, Gatell JM: Substitution of nevirapine, efavirenz, or abacavir for protease inhibitors in patients with human immunodeficiency virus infection. N Engl J Med 2003, 349:1036-1046.
25. World Health Organization: International Statistical Classification of Diseases and Health Related Problems, ICD-9; 9th revison. Geneva: World Health Organization; 1979

26. World Health Organization: International Statistical Classification of Diseases and Health Related Problems, ICD-10; 10th revision. Geneva: World Health Organization; 2007.

27. Des Jarlais DC, Feelemyer JP, Modi SN, Arasteh K, Hagan H: Are females who inject drugs at higher risk for HIV infection than males who inject drugs: an international systematic review of high seroprevalence areas. Drug Alcohol Depend 2012, 124:95-107.

28. Nunes EV, Rounsaville BJ: Comorbidity of substance use with depression and other mental disorders: from Diagnostic and Statistical Manual of Mental Disorders, fourth edition (DSM-IV) to DSM-V. Addiction 2006, 101(Suppl):89-96.

29. Schuckit MA: Comorbidity between substance use disorders and psychiatric conditions. Addiction 2006, 101(Suppl):76-88.

30. Gibson A, Randall D, Degenhardt L: The increasing mortality burden of liver disease among opioid-dependent people: cohort study. Addiction 2011, 106:2186-2192.

31. Rosca P, Haklai Z, Goldberger N, Zohar P, Margolis A, Ponizovsky AM Mortality and causes of death among users of methadone maintenance treatment in Israel, 1999-2008. Drug Alcohol Depend 2012, 125:160-163.

32. Sangsari S, Milloy M-J, Ibrahim A, Kerr T, Zhang R, Montaner J, Wood E: Physician experience and rates of plasma HIV-1 RNA suppression among illicit drug users: an observational study. BMC Infect Dis 2012, 12:22.

33. Huang CL-C, Lee CW: Factors associated with mortality among heroin users after seeking treatment with methadone: a population-based cohort study in Taiwan. J Subst Abuse Treat 2013, 44:295-300.

34. Sanvisens A, Bolao F, Vallecillo G, Torrens M, Fuster D, Pérez-Hoyos S, Tor J, Rivas I, Muga R: HIV Infection and Viral Hepatitis in Drug Abusers. In Curr Perspect HIV Infect. Edited by Saxena S. Rijeka: Intech; 2013:367-384.

35. Kellogg TA, McFarland W, Perlman JL, Weinstock H, Bock S, Katz MH, Gerberding JL, Bangsberg DR: HIV incidence among repeat HIV testers at a county hospital, San Francisco, California, USA. J Acquir Immune Defic Syndr 2001, 28:59-64.

36. Galea S, Vlahov D: Social determinants and the health of drug users: socioeconomic status, homelessness, and incarceration. Public Health Rep 2002, 117(Suppl):S135-S145.

37. Observatorio Español sobre Drogas (OED): Informe $N^{\circ}$ 6. Madrid: Plan Nacional sobre Drogas; 2003

38. Sánchez-Niubò A, Domingo-Salvany A, Melis GG, Brugal MT, Scalia-Tomba G: Two methods to analyze trends in the incidence of heroin and cocaine use in Barcelona [Spain]. Gac Sanit 2007, 21:397-403.

39. Hedden SL, Martins SS, Malcolm RJ, Floyd L, Cavanaugh CE, Latimer WW: Patterns of illegal drug use among an adult alcohol dependent population: results from the National Survey on Drug Use and Health. Drug Alcohol Depend 2010, 106:119-125.

40. Cousins G, Teljeur C, Motterlini N, McCowan C, Dimitrov BD, Fahey T: Risk of drug-related mortality during periods of transition in methadone maintenance treatment: a cohort study. J Subst Abuse Treat 2011, 41:252-260.

doi:10.1186/1471-2334-14-504

Cite this article as: Muga et al:: Sex-specific disease outcomes of HIV-positive and HIV-negative drug users admitted to an opioid substitution therapy program in Spain: a cohort study. BMC Infectious Diseases 2014 14:504. 